\title{
Apakah Reputasi Perusahaan Menghasilkan Laba yang Berkualitas di Indonesia?
}

\author{
Agung Prasetyo Nugroho Wicaksono ${ }^{\mathrm{a},{ }^{*}}$ and Dhaniel Syam ${ }^{\mathrm{b}}$ \\ a Accounting Department, University of Muhammadiyah Malang, agungpnw@umm.ac.id, Indonesia \\ b Accounting Department, University of Muhammadiyah Malang, daniel@umm.ac.id, Indonesia
}

\begin{abstract}
This study examines how the influence of a company's reputation on the quality of earnings generated from financial statements. The research data used are secondary data in the form of annual reports and financial reports from the Indonesia Stock Exchange within a period of 3 years (2016 - 2018). The research sample is non-financial sector companies listed on the Indonesia Stock Exchange. The main variable in this study is the company's reputation as an independent variable and earnings quality as the dependent variable. The control variables used in this study are asset growth, company size and ROA. Panel data regression was used as a tool to test the hypotheses of this study.
\end{abstract}

Keywords: Corporate Reputation; Earning Quality, Quality of Financial Statements 


\section{Pendahuluan}

Pada era 2000'an, berbagai kasus skandal keuangan terjadi yang melibatkan korporasi besar seperti Worldcom, Enron, Parmalat, Xerox dan lain sebagainya yang memunculkan opini public bahwasanya manajer melakukan tindakan yang oportunis agar memperoleh keuntungan pribadi semaksimal mungkin yang berdampak kepada munculnya regulasi seperti Sarbane-Oxley Act untuk mengantisipasi kasus-kasus serupa tidak terulang kembali dimasa yang akan datang (Jiraporn et al., 2008). Dengan adanya regulasi itu, mewajibkan agar perusahaan mampu memaksinalkan fungsi pengawasan terhadap manajemen didalam aktivitas pengelolaan keuangan perusahaanya agar menghasilkan laporan keuangan yang baik, berkualitas dan memberikan informasi yang terpecaya kepada public.

Penelitian ini merupakan pengembangan dari penelitian Luchs et al. (2009) yang menguji reputasi perusahaan dengan menggunakan proxy majalah Fortune "America's Most Admired Companies" serta menggunakan modified jones model sebagai proksi dari kualitas laba. Hasil penelitian Luchs et al. (2009) sesuai dengan hipotesis yang diajukan, bahwasanya manajer berusaha untuk mempertahankan atau membangun reputasi perusahaan tersebut agar kinerja operasional menghasilkan laba yang optimal, berkualitas, serta mendapatkan kepercayaan dari berbagai pihak.

Penelitian ini menggunakan hasil riset yang dipublish di artikel dari Media Bisnis Indonesia yang berjudul "100 excellent growth company ranks 2018" sebagai proxy variable reputasi perusahaan. Hasil dari riset tersebut menunjukan bahwa terdapat 100 perusahaan dari 566 perusahaan dengan kinerja yang terbaik berdasasarkan naik turunya kondisi perekonomian yang menerpa Indonesia beberapa tahun terakhir. Kemudian menggunakan modified jones model sebagai proxy pengukuran kualitas laba yang diharapkan mampu mengidentifikasi keberadaan adanya manajemen laba atau tidak dengan menghitung discretional accrual. Nilai absolute dari discretional accrual dianggap sebagai ukuran terbalik dari kualitas laba. Artinya bahwa nilai absolute yang lebih tinggi dari discretional accrual manunjukan kualitas laba yang lebih rendah.

\section{Literatur Review dan Rumusan Hipotesis}

Kualitas laba merupakan indikator dari kualitas informasi keuangan yang berasal dari refleksi kebenaran laba perusahaan (Bellovary et al., 2005). Kualitas laba juga merupakan aspek penting di dalam mengevaluasi kesehatan keuangan suatu entitas, namun investor, kreditor dan pengguna laporan keuangan lainya sering mengabaikanya. Kualitas laba mengacu kepada kemampuan laba yang dilaporkan untuk mencerminkan laba perusahaan yang sebenarnya, serta keugunaan laba yang dilaporkan untuk memprediksi dimasa depan. Kualitas laba juga mengacu kepada stabilitas, namun evaluasi terhadap stabilitas itu seringkali dirasa sulit karena perusahaan menyoroti berbagai angka penilaian, diantaranya aadalah pendapatan operasional, laba bersih, dan pendapatan proforma. Selain itu perusahaan sering menghitung angka penilaian tersebut secara berbedabeda. Sehingga membuat laba rugi tidak berguna di dalam memprediksi laba di masa depan. Perusahaanperusahaan yang sudah memiliki brand value atau market value yang tinggi diharapkan telah memiliki kualitas laba yang baik dimana mereka harus menjaga stabilitas mereka di pasar baik dimata public, stakeholder, investor,dan kreditor.

Reputasi perusahaan merupakan keseluruhan dari estimasi perusahaan yang dipegang oleh konstitusinya. Reputasi perusahaan menggambarkan mengenai hasil afektif atau reaksi emosional seperti gambaran baik buruknya perusahaan, kuat lemahnya perusahaan dipandang dari perspektif konsumen, investor, karyawan, serta masyarakat public (Fombrun et al., 1996; Van Riel et al., 2007). Reputasi tergambar secara menyeluruh dan memberikan kesan yang jelas dari kelompok tertentu terhadap perusahaan, sebagai hasil dari pengolahan informasi yang dilakukan oleh mereka (Alvesson, 1990). Reputasi juga merupakan sekumpulan arti mengenai bagaimana perusahaan itu dikenal dan bagaimana pandangan dari masyarakat public terkait kondisi perusahaan tersebut. Hal itu dapat dilihat dari ide atau gagasan perusahaan yang dapat diterima oleh public sehingga memberikan kesan public yang positif terhadap perusahaan tersebut (Dowling, 1986; Roberts et al., 2002). Reputasi perusahaan juga mengacu kepada ekspetasi, attitude, dan berbagai pendapat dari public secara natural berdasarkan pada 
realita yang menunjukan identitas perusahaan (Topalian, 1984).

Roberts et al. (2002) dan De Castro et al. (2006) menguji bahwasanya reputasi perusahaan mempengaruhi kinerja kuangan secara positif. Perusahaan yang telah bereputasi baik akan lebih mampu mempertahankan keunggulan profitabilitasnya dari waktu ke waktu, kemudian memiliki keunggulan pembiayaan, serta lebih disukai oleh vendor karena bebas dari pelanggaran kontrak supply. Kemudian penelitian yang telah dilakukan oleh Klassen et al. (1996) menyatakan bahwa perusahaan yang paling dikagumi akan tumbuh lebih cepat karena cenderung melakukan berbagai macam akuisisi agar perusahaan mampu meningkatkan kinerja secara maksimal demi menghasilkan laba yang optimal. Tentunya hal tersebut sangat menguntungkan bagi perusahaan.

Anderson et al. (2006) telah melakukan penelitian terkait dengan portofolio saham dimana harga saham perusahaan yang bereputasi baik telah menggunguli harga-harga saham perusahaan lainya pada bursa saham. Smith et al. (2010) juga melakukan penelitian yang sama namun dengan menggunakan model Ohlson (1995) memberikan informasi bahwa perusahaan yang bereputasi telah memiliki rata-rata nilai premi pasar sekitar 1,3 milliar US dollar. Hal itu tentunya mengindikasi bahwa perusahaan yang bereputasi sangat dihargai oleh para investor dan juga pasar modal.

J. R. Francis et al. (2008) menguji bagaimana pengaruh reputasi perusahaan terhadap kualitas laba dimana menggunakan persepsi pers atau media terhadap CEO perusahaan tersebut sebagai proxy dari reputasi perusahaan dan proxy discretional accrual sebagai pengukuruan kualitas laba. Hasil dari penelitian tersebut menemukan bahwa CEO yang lebih dikenal oleh para pers akan menghasilkan kualitas laba yang baik serta nilai discretional accrual yang tinggi.

Luchs et al. (2009) juga meneliti bagaimana dampak reputasi perusahaan terhadap kualitas laba dengan mengunakan ukuran public sebagai proxy pengukuran reputasi perusahaan. hasil dari penelitian menunjukan bahwa perusahaan yang terdaftar pada America's Most Admired Companies tahun 2006 telah memiliki laba yang berkualitas dengan nilai dicretional accrual yang tinggi pula.

Berdasarkan penjelasan diatas, maka hipotesis penelitian adalah :

$\mathrm{H}_{1}$ : adanya reputasi perusahaan berpengaruh positif terhadap kualitas laba.

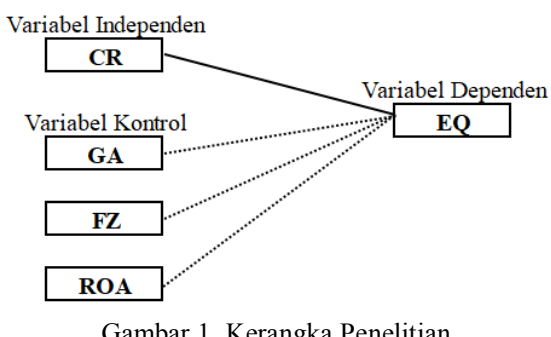

\section{Metodologi Penelitian}

\section{Populasi dan Sampel Penelitian}

Populasi penelitian yang digunakan adalah seluruh perusahaan yang terdaftar pada bursa efek Indonesia untuk kurun waktu tiga tahun, yaitu mulai dari tahun 2016 sampai 2018. Kemudian dilakukan pemilihan sampling dengan tidak menggunakan sektor jasa keuangan karena keterbatasan memperoleh informasi dan keterbatasan peneliti didalam memahami struktur laporan keuangan perusahaan sector jasa keuangan.

Tabel 1

Kriteria Pemilihan Sampel

\begin{tabular}{|c|c|c|}
\hline Kriteria & & $\begin{array}{c}\text { Total } \\
\text { sampel }\end{array}$ \\
\hline $\begin{array}{l}\text { - Seluruh perusahaan } \\
\text { yang terdaftar pada } \\
\text { bursa } \\
\text { Indonesia untuk } \\
\begin{array}{l}\text { periode tahun } \\
2016 \\
-2018\end{array}\end{array}$ & 627 perusahaan $* 3$ tahun & 1.881 \\
\hline $\begin{array}{l}\text { - Perusahaan sector } \\
\text { jasa keuangan } \\
\text { - Ketidaklengkapan } \\
\text { dan Ketidaksediaan } \\
\text { informasi data yang } \\
\text { diperlukan }\end{array}$ & $\begin{array}{l}\text { (91 perusahaan } * 3 \text { tahun) } \\
\text { (152 perusahaan } * 3 \text { tahun) }\end{array}$ & (273) \\
\hline Sampel akhir & 384 perusahaan $* 3$ tahun & $\begin{array}{c}1.152 \\
\text { sampel }\end{array}$ \\
\hline
\end{tabular}

\section{Variabel Penelitian}

Variabel dependen yang digunakan dalam penelitian ini adalah kualitas laba yang diukur dengan discretionary accrual (DA) menggunakan modified jones model (Jones, 1991; Luchs et al., 2009) yang kemudian diabsolutekan, dimana nilai DA diperoleh dari :

$$
\mathrm{DA}_{\mathrm{it}}=\mathrm{TA}_{\mathrm{it}} / \mathrm{A}_{\mathrm{it}-1}-\mathrm{NDA}_{\mathrm{it}}
$$


Nilai $\mathrm{TA}_{\mathrm{it}}$ diperoleh dari :

$$
\mathrm{TA}_{\mathrm{it}}=\mathrm{NI}_{\mathrm{it}}-\mathrm{CFO}_{\mathrm{it}}
$$

Nilai $\mathrm{NDA}_{\text {it }}$ diperoleh dari:

$$
\begin{aligned}
& \mathrm{NDA}_{\text {it }}=\beta_{1}\left(1 / \mathrm{A}_{\mathrm{it}-1}\right)+\beta_{2}\left(\Delta \mathrm{Rev}_{\mathrm{it}} / \mathrm{A}_{\mathrm{it}-1}-\Delta \mathrm{Rec}_{\mathrm{it}} / \mathrm{A}_{\mathrm{it}-}\right. \\
& \left.{ }_{1}\right)+\beta_{3}\left(\mathrm{PPE}_{\mathrm{it}} / \mathrm{A}_{\mathrm{it}-1}\right)
\end{aligned}
$$

Dimana untuk mencari nilai beta $\left(\beta_{1}, \beta_{2}, \beta_{3}\right)$, perlu dilakukan uji regresi linear berganda dari :

$$
\begin{aligned}
& \mathrm{TA}_{\mathrm{it}} / \mathrm{A}_{\mathrm{it}-1}=\beta_{0}+\beta_{1}\left(1 / \mathrm{A}_{\mathrm{it}-1}\right)+\beta_{2}\left(\Delta \mathrm{Rev}_{\mathrm{it}} / \mathrm{A}_{\mathrm{it}-1}\right)+\beta_{3}\left(\mathrm{PPE}_{\mathrm{it}}\right. \\
& \left(\mathrm{A}_{\mathrm{it}-1}\right)+\varepsilon
\end{aligned}
$$

Penjelasan :

$\mathrm{DA}_{\mathrm{it}}=$ Discretionary Accruals perusahaan i pada periode ke $\mathrm{t}$

$\mathrm{TA}_{\mathrm{it}} \quad=$ Total akrual perusahaan i pada tahun $\mathrm{t}$

$\mathrm{A}_{\mathrm{it}-1}=$ Total aktiva perusahaan $\mathrm{i}$ pada periode $\mathrm{ke}$ $\mathrm{t}-1$

$\mathrm{NDA}_{\text {it }}=$ Non Discretionary Accruals perusahaan i pada periode ke $\mathrm{t}$

$\mathrm{NI}_{\mathrm{it}}=$ Laba bersih perusahaan i pada periode ke$\mathrm{t}$

$\mathrm{CFO}_{\text {it }}=$ Aliran kas dari aktivitas operasi perusahaan i pada periode ke $t$

$\beta=$ Beta

$\Delta \operatorname{Rev}_{\text {it }}=$ Perubahan pendapatan perusahaan i pada periode ke $\mathrm{t}$

$\Delta \operatorname{Rec}_{i t}=$ Perubahan pinjaman perusahaan $\mathrm{i}$ pada periode ke $\mathrm{t}$

$\mathrm{PPE}_{\mathrm{it}}=$ Aktiva tetap (property, plant, equipment) perusahaan i pada periode ke $\mathrm{t}$

$\varepsilon_{\text {it }} \quad=$ Error

Variabel independent yang digunakan dalam penelitian ini adalah reputasi perusahaan yang diukur dengan variable dummy, pemberian skor 1 jika sampel termasuk didalam kategori 100 perusahaan terbaik, dan pemberian nilai skor 0 jika tidak termasuk. Kemudian variable control yang digunakan adalah variable pertumbuhan asset, ukuran perusahaan dan return on assets (ROA).

\section{Model Penelitian}

Model penelitian yang digunakan dalam penelitian ini adalah sebagai berikut:

$\mathrm{EQ}_{\mathrm{it}}=\beta_{0}+\beta_{1} \mathrm{CR}_{\mathrm{it}}+\beta_{2} \mathrm{GA}_{\mathrm{it}}+\beta_{3} \mathrm{FZ}_{\mathrm{it}}+\beta_{4} \mathrm{ROA}_{\mathrm{it}}+\mathrm{e}_{\mathrm{it}}$
Penjelasan :

$\mathrm{EQ}_{\text {it }}$ : kualitas laba dengan menggunakan modified model Jones perusahaan i tahun $\mathrm{t}$

$\mathrm{CR}_{\text {it }} \quad$ : reputasi perusahaan perusahaan $\mathrm{i}$ tahun $\mathrm{t}$

$\mathrm{GA}_{\text {it }}$ : pertumbuhan asset perusahaan i tahun $\mathrm{t}$

$\mathrm{FZ}_{\text {it }} \quad$ : ukuran perusahaan perusahaan i tahun $\mathrm{t}$

$\mathrm{ROA}_{\text {it }}$ : return on asset perusahaan $\mathrm{i}$ tahun $\mathrm{t}$

$\mathrm{e}_{\mathrm{it}} \quad$ : error $_{\mathrm{it}}$

\section{Hasil Dan Pembahasan}

\begin{tabular}{|c|c|c|c|c|}
\hline $\begin{array}{l}\text { Kategori } \\
\text { test }\end{array}$ & $\begin{array}{ll}\text { Cross } & \text { Sec } \\
\text { Chi Sq } & \end{array}$ & $\begin{array}{l}\text { Cross } \\
\text { Random } \\
\text { Sq }\end{array}$ & $\begin{array}{l}\text { Sec. } \\
\text { Chi }\end{array}$ & $\begin{array}{l}\text { Kesimpulan } \\
\text { model }\end{array}$ \\
\hline Chow Test & $\begin{array}{l}2244.797343 \\
\text { (Prob : }\end{array}$ & & & \\
\hline & $0.00001)$ & & & Random Effect \\
\hline Hausmann & & 1.614717 & & Model \\
\hline Test & & $\begin{array}{l}\text { (Prob } \\
0.6561)\end{array}$ & : & \\
\hline
\end{tabular}

Uji Pemilihan Model Panel

Berikut adalah hasil uji pemilihan model data panel:

Tabel 2

Uji pemilihan model

Berdasarkan tabel 2, disimpulkan bahwa model data panel yang terpilih adalah model uji Random Effect Model (REM) dengan nilai uji hausmann Prob Chi square 0.6561 (Prob >0.05).

\section{Hasil uji regresi dan uji hipotesis}

Berikut adalah hasil uji regresi panel beserta uji hipotesis:

Tabel 3

Hasil uji panel dan uji hipotesis

\begin{tabular}{lllll}
\hline Variabel & & Random Effect & $\begin{array}{l}\text { Kesimpulan } \\
\text { Hipotesis }\end{array}$ & Uji \\
\hline Intercept & Coef & $191689.9^{* * *}$ & \\
& t-stat & 10.41689 & \\
X1_CR & & $20989.96^{* * *}$ & $\mathrm{H}_{1}$ diterima \\
& & 6.721763 & \\
& & & \\
\hline
\end{tabular}




\begin{tabular}{|c|c|c|c|}
\hline Variabel & Random Effect & $\begin{array}{l}\text { Kesimpulan } \\
\text { Hipotesis }\end{array}$ & Uji \\
\hline X2_GA & $\begin{array}{l}1460.905 \\
1.030571\end{array}$ & & \\
\hline X3_FZ & $\begin{array}{l}-6808.261^{* * *} \\
-10.43915\end{array}$ & & \\
\hline X4_ROA & $\begin{array}{l}-0.003591 \\
-0.065367\end{array}$ & & \\
\hline $\begin{array}{l}\text { Adj R square } \\
\text { F-stat }\end{array}$ & $\begin{array}{l}0.087282 \\
28.51698^{* * *}\end{array}$ & & \\
\hline $\begin{array}{l}* * * \text { (significant } 1 \%) \\
* *(\text { significant } 5 \%) \\
*(\text { significant } 10 \%)\end{array}$ & & & \\
\hline
\end{tabular}

Kemudian hasil Random Effect Model dari tabel 3 menyimpulkan bahwa perusahaan yang bereputasi telah memiliki laba yang berkualitas. Hal itu dibuktikan dengan nilai coefficient dari variabel $\mathrm{CR}$ (reputasi perusahaan) yang positif secara signifikan senilai 20989.96 dengan sig 0.002 (prob $<0.01$ ), sehingga menyimpukan bahwa perusahaan yang bereputasi telah meningkatkan nilai absolute discretional accrual sehingga kualitas laba yang dihasilkan baik karena meningkatnya nilai dicretional accrual menandakan bahwa perusahaan dominan meninggikan informasi labanya agar mendapatkan respon positif dari publik dan investor. Hasil uji $\mathrm{F}$ juga signifikan, menandakan bahwa secara keseluruhan variabel independent penelitian mempengaruhi variabel dependen. Kontibusi model penelitian yang digunakan cukup kecil sebesar $8 \%$, maka diasumsikan masih banyak variable lain yang mampu mendeteksi kualitas laba diluar model yang diujikan. Variabel kontrol yang digunakan hanya variabel ukuran perusahaan saja yang berpengaruh negatif secara signifikan, sisanya yaitu variabel pertumbuhan aset dan ROA tidak signifikan sehingga disimpulkan bahwa hanya variabel ukuran perusahaan mampu mengurani nilai absolute discretional accrual.

\section{Kesimpulan}

Penelitian ini menganalisis apakah perusahaan yang bereputasi pada Bursa Efek Indonesia telah menghasilkan laba yang berkualitas. Dengan mengembangkan penelitian yang telah dilakukan sebelumnya oleh (Luchs et al., 2009) yang hanya menggunakan kurun waktu satu tahun melalui metode OLS, maka dengan model data panel yang digunakan dalam penelitian ini diharapkan mampu menjawab fenomena secara lebih akurat serta merefleksikan kondisi sebenarnya di Indonesia. Hasil dari penelitian ini mendukung penelitian yang dilakukan oleh Luchs et al. (2009) dan J. R. Francis et al. (2008) bahwa adanya reputasi perusahaan berpengaruh secara positif signifikan terhadap kualias laba. Hal tersebut menunjukan bahwa adanya perusahaan yang bereputasi di Indonesia berdasarkan majalah Media Bisnis Indonesia yang berjudul " 100 Excellent Growth Company Ranks 2018" telah menghasilan laba yang berkualitas didukung dengan nilai DA yang tinggi $(\mathrm{DA}>0)$ dimana perusahaan lebih mengutamakan melaporkan laba perusahaanya yang cukup besar agar mampu mendapatkan respon positif dari berbagai pihak.

Keterbatasan penelitian ini adalah hanya menggunakan satu pengukuran dalam menentukan kualitas laba. Diharapkan penelitian selanjutnya mampu menggunakan proxy pengukuran lainya bahkan menggunakan dua atau lebih di dalam menentukan kualitas laba (Bellovary et al., 2005; J. Francis et al., 2004; Givoly et al., 2010). Kemudian kontribusi variable independent perlu ditambahkan dengan variable lainya yang diprediksi mampu mengurangi nilai discretional accrual.

\section{Referensi}

Alvesson, M. J. O. s. (1990). Organization: from substance to image? , 11(3), 373-394

Anderson, J., \& Smith, G. J. F. A. J. (2006). A great company can be a great investment. $62(4), 86-93$.

Bellovary, J. L., Giacomino, D. E., \& Akers, M. D. J. T. C. J. (2005). Earnings quality: It's time to measure and report. 75(11), 32 .

De Castro, G. M., López, J. E. N., \& Sáez, P. L. J. J. o. b. e. (2006). Business and social reputation: Exploring the concept and main dimensions of corporate reputation. 63(4), 361-370.

Dowling, G. R. J. I. m. m. (1986). Managing your corporate images. 15(2), 109-115.

Fombrun, C. J., \& Rindova, V. J. N. Y. U., Stern School of Business, Working Paper. (1996). Who's tops and who decides? The social construction of corporate reputations. 5-13.

Francis, J., LaFond, R., Olsson, P. M., \& Schipper, K. J. T. a. r. (2004). Costs of equity and earnings attributes. 79(4), 967-1010.

Francis, J. R., \& Wang, D. (2008). The joint effect of investor protection and Big 4 audits on earnings quality around the world. Contemporary accounting research, 25(1), 157-191.

Givoly, D., Hayn, C. K., \& Katz, S. P. J. T. a. r. (2010). Does public ownership of equity improve earnings quality? , 85(1), 195225 . 
Jiraporn, P., Miller, G. A., Yoon, S. S., \& Kim, Y. S. J. I. R. o. F. A. (2008). Is earnings management opportunistic or beneficial? An agency theory perspective. $17(3), 622-634$.

Jones, J. J. (1991). Earnings management during import relief investigations. Journal of accounting research, 29(2), 193-228.

Klassen, R. D., \& McLaughlin, C. P. J. M. s. (1996). The impact of environmental management on firm performance. 42(8), 1199 1214

Luchs, C., Stuebs, M., \& Sun, L. (2009). Corporate reputation and earnings quality. Journal of Applied Business Research, 25(4), 47.

Ohlson, J. A. J. C. a. r. (1995). Earnings, book values, and dividends in equity valuation. 11(2), 661-687.
Roberts, P. W., \& Dowling, G. R. J. S. m. j. (2002). Corporate reputation and sustained superior financial performance. 23(12), 1077-1093.

Smith, K. T., Smith, M., \& Wang, K. J. J. o. S. M. (2010). Does brand management of corporate reputation translate into higher market value? , 18(3), 201-221.

Topalian, A. J. I. J. o. A. (1984). Corporate identity: beyond the visual overstatements. 3(1), 55-62.

Van Riel, C. B., \& Fombrun, C. J. (2007). Essentials of corporate communication: Implementing practices for effective reputation management: Routledge. 